Tian, H., Dogbe, C. S. K, Bamfo, B. A., Pomegbe, W. W. K., \& Borah, P. S. (2021). Assessing the Intermediary Role of Relationship Ending Capability and Dark Side Between Network Embeddedness and SMEs' Innovation Performance. Journal of Competitiveness, 13(1), 146-163. https://doi.org/10.7441/ joc.2021.01.09

\title{
Assessing the Intermediary Role of Relationship Ending Capability and Dark Side Between Network Embeddedness and SMEs' Innovation Performance
}

\author{
- Hongyun Tian, Courage Simon Kofi Dogbe*, Bylon Abeeku Bamfo, \\ Wisdom Wise Kwabla Pomegbe, Prasad Siba Borah
}

\begin{abstract}
A key driver of firm competitive advantage is the firm's ability to develop along with the everchanging business environment and associated market demands by being innovative. Small and medium-sized enterprises (SMEs), however, often lack adequate resources to develop innovation, so they search for external resources to augment the deficiency of their internal resources. Network embeddedness has many advantages for the firm, but it also has a dark side which has a negative effect on the network relationship. In order to take advantage of a network, firms should cultivate the capability to deal with the dark side of inter-firm relationships. Firstly, this study assesses the effect of network embeddedness on the innovation performance of SMEs. Secondly, the authors investigated the moderating role of this dark side in the relationship between network embeddedness and the innovation performance of SMEs. Finally, the role of relationship ending capability in neutralizing the negative effect of dark side we presented. Empirical analysis was based on 388 SMEs. Various validity and reliability checks were conducted before the presentation of the analysis itself, which was conducted using the ordinary least squares approach in SPSS (v.23). The findings showed the dark side negatively moderated the relationship between network embeddedness and the innovation performance of SMEs. This negative effect is, however, reduced by SMEs with a high relationship ending capability by freeing up firm's limited resources for more fruitful business relationships.
\end{abstract}

Keywords: competitiveness, network embeddedness, innovation performance, relationship ending capability darkside, SMEs.

JEL Classification: L11, D24, D8, L22

Received: December, 2019

1st Revision: July, 2020

Accepted: September, 2020

\section{INTRODUCTION}

A key driver of firm competitive advantage is the firm's ability to develop along with the everchanging business environment and associated market demands by being innovative. (Hoholm 
\& Olsen, 2012). Innovation could prove to be resource-intensive at times, however, and as such alliances and firm associations offer firms access to innovation resources such as knowledge, technology and human resources (Huang \& Rice, 2012). The first contribution of the present study is to introduce the role of network embeddedness in the innovation performance of small and medium-sized enterprises (SMEs). Quite often, SMEs lack sufficient internal resources to develop innovation, so they seek resources outside the firm to augment their internal resources (Hvolkova et al., 2019). Xiaobao et al. (2013) have indicated that SMEs consider external network information as means of obtaining access to marketing and sales channels for innovation. Network embeddedness is defined as "the structure of a firm's relationship with other firms - specifically, the extent to which a firm is connected to other firms" (Echols \& Tsai, 2005). Although a number of past studies have identified the relationship between network embeddedness and innovation performance as positive (Dogbe et al., 2020b), not all inter-organizational relationships play a positive role in innovation performance (Wang \& Chen, 2012). There are some negative aspects of network which may have a detrimental effect on firm performance, which studies have referred to as the "dark side" of business relationships. The second contribution of this study considers the negative moderating effects of the so-called dark side in the relationship between network embeddedness and the innovation performance of SMEs.

This dark side is defined as challenges, problems, drawbacks and / or difficulties emanating from structural issues in business relationships, which may be voluntary or involuntary (Abosag et al., 2016). More specifically, these issues may be influenced by power imbalances, business processes within the relationship, market dynamics, competitiveness, capability development, and other such factors. The dark side of a relationship has been considered in terms of relationship tensions (Fang et al., 2011), while many other studies have focused on opportunistic behavior (Abosag et al., 2016). The present study also defines the dark side in terms of opportunism in business relationships, following researchers like Yang \& Wang (2013), who have indicated how opportunism is a true dark force that negatively influences business relationships. SMEs become embedded in business networks to draw resources such as knowledge and technology to support innovation, which is expected to stem from a positive relationship (Xiaobao et al., 2013). Nevertheless, the dark side of these network relationships has also shown negative influences in terms of the relationship between network embeddedness and the innovation performance of SMEs (Abosag et al., 2016).

The potential for a dark side within a business relationship is quite inevitable, as Anderson \& Jap (2005) have indicated that "relationships that appear to be doing well are often the most vulnerable to the forces of destruction that are quietly building beneath the surface of the relationship." The third contribution of this study, therefore, focuses on how SMEs with relationship ending capability could neutralize the negative effect of dark side to facilitate an enhanced innovation performance. A key mechanism that might serve to explain the crucial role of relationship ending capability for firm innovation performance is the concept of the termination of unfavorable business relationship as freeing resources which can be used to engage in a new business relationship to draw innovation resources (Padula, 2008). The term relationship ending indicates that all resource ties have been severed and all cooperative activities have been terminated between the organizations (Tähtinen \& Halinen-Kaila, 2002). It is, therefore, 
expected that SMEs with relationship ending capability will be able to overcome negative effects of the dark side in the relationship between network embeddedness and innovation performance by cutting ties with members in the network engaging in opportunistic behaviors and practices. Figure 1 presents the theoretical framework of the study.

\section{THEORETICAL BACKGROUND}

\subsection{Network embeddedness and the innovation performance of SMEs}

Social capital scholars have highlighted how network embeddedness influences various aspects of firm innovation (Lin et al., 2009). Social capital is a valuable asset drawn from access to resources made available in social relationships (Pèrez-Luño et al., 2011). Social capital is essential in network relationships, although it has no exclusive ownership. Nahapiet \& Ghoshal (1998) present social capital as a key to achieving institutional dynamism, value creation and innovation. Although social capital may not be exclusive to a specific firm within a network, all network actors, e.g. SMEs, have the potential to complement their internal resources with the external resources drawn from the network to develop unique competences for their innovation agenda. In terms of resource-based theory (RBT), these unique resources and capabilities help firms achieve competitive advantages in their operations (Barney, 1991), including their innovation agenda. RBT is used to assess the use of the firm's unique tangible and intangible resources to achieve organizational performance (Cortez \& Johnston, 2019).

Past studies have divided network embeddedness into three dimensions: relational, structural, and cognitive (Nahapiet \& Ghoshal, 1998). Relational embeddedness represents the processes involved in developing a shared understanding and unity among network actors (Wang \& Chen, 2012). Relational embeddedness is founded on the perception of closeness and trust among network members. Relational closeness represents the level of familiarity within the network, which can help to define the willingness of the firms to share resources (knowledge, technology or people) with other members in the network. Similarly, when there is high relational trust among network members, both adaptive and interactive knowledge exchanges have been shown to increase, resulting in greater innovation output for firms.

Structural embeddedness focuses on the informational role associated with the position occupied by a firm in the network (Gulati \& Singh, 1998). Structural embeddedness is characterized by centrality, autonomy, equivalence and density (Wang \& Chen, 2012). Centrality represents the strategic position occupied by the focal firm in the network as defined by the level and degree of its involvement in significant ties (Gnyawali \& Madhavan, 2001). Occupying a strategic position within a network grants the focal firm access to efficient and effective knowledge. As indicated by Gnyawali \& Madhavan (2001), "a structurally autonomous actor has structural holes between the actors it is connected to but is free of structural holes at its own end." Structural holes enable the focal firm to achieve advantages by drawing innovation knowledge and resources from unconnected groups. Structural equivalency is achieved when actors in a network have identical ties to and from all other members in the network (Wasserman \& Faust, 1994). Network density is considered the "extent of interconnection among the actors of the network-the 
greater the interconnectedness, the higher the density" (Gnyawali \& Madhavan, 2001). A highly dense network enhances the fast and efficient flow of knowledge and other innovation resources due to the high interconnections and shared routines of informing gathering and distribution (Valente, 2005).

Similarly, cognitive embeddedness is defined as the resources provided through shared meaning and understanding among network members, creating a situation which is based on shared culture, goals, and technological distance (Wang \& Chen, 2012). Shared culture represents the degree to which the network members have common norms of behavior, while shared goals represent the extent to which network actors share a common approach and understanding in achieving network objectives and tasks. Cognitive distance explains differences in the technological knowledge and expertise among network members (Gilsing et al., 2008), of which higher technological distance indicates less cognitive embeddedness.

Overall, network embeddedness has been identified to influence diverse aspects of firms' innovation. Wang \& Chen (2012) found out that network embeddedness has an influence on disruptive innovation in an open innovation arena. Network embeddedness facilitates the transfer of technological knowledge for firm innovation (Lin et al., 2009). Network embeddedness does not just influence knowledge transfer, but also has a direct impact on joint innovation success (Liu et al., 2019). Firms in a network are able to draw innovation knowledge for their new product development (Dogbe et al., 2020b). Yan \& Guan (2018) also found out that network embeddedness has an effect on firms' exploitative and exploration innovation. From these studies, it is evident that is SMEs are effectively embedded in a network, they have access to the resources to facilitate their new product innovativeness and innovation speed. As SMEs occupy favorable position in the network with common goals and norms founded on trust, external resources will be placed at their disposal for innovation performance. The motivation of actors to share knowledge for successful innovation is thus dependent on network structure, cognition, and interpersonal relations (Hortoványi \& Szabó, 2006). We thus state the first hypothesis as follows:

H1: Network embeddedness has a significant effect on the innovation performance of SMEs.

\subsection{Moderating Role of Dark Side}

In business-to-business relationship literature, the term dark side first emerged in the mid to late 1990s (Abosag et al., 2016), focusing on drawbacks relating to structural issues in business relationships such as power imbalance, size difference, business processes, market dynamics, capability development, competitiveness, etc. (Anderson \& Jap, 2005). Dark side is considered inevitable in business relationships as it forms the very fabric of every relationship (Hawkins et al., 2013). Anderson \& Jap (2005) indicated that "relationships that appear to be doing well are often the most vulnerable to the forces of destruction that are quietly building beneath the surface of the relationship." This problem is referred to as "hidden costs of trust" (Selnes $\&$ Sallis, 2003), as a person's trust in you results in a position far more vulnerable than that of a stranger (Granovetter, 1985). Studies, such as Crosno \& Dahlstrom (2008), have presented opportunism as the true dark force that negatively affects business relationship. Luo (2006) indicated that strong forms of opportunism violate contractual norms, whiles weak forms of 
opportunism also violates relational norms. Opportunism is defined as "self-interest seeking with guile" in business relationship (Williamson, 1975).

As for outsourcing relationship, Tsai et al. (2012) found out that the relationship and asset risk affect the success of business process outsourcing. In a business-to-business innovation relationship, Noordhoff et al. (2011) revealed that strong ties negatively influence the amount of innovation knowledge drawn from customers by suppliers because of fear of customer opportunism. Collaboration with competitors (coopetition) presents the focal firm with new opportunities, capabilities and resources, however, there are some dark sides that negate this positive effect when there is too much coopetition. Fang et al. (2011) found out that the positive relationship between relationship quality and relationship function is somewhat affected by relationship tensions. Villena et al. (2011) identified that buyer-supplier relationship has both bright and dark side, as inverted U-shape relationship was found between social capital and business performance. Regarding, international export and import business relationship, Pressey \& Tzokas (2004) found out that relationships are weakened over time because of reduced affective commitment. This thus affects the relationship performance in the long-term. In the service ecosystems, Mele et al. (2018) found the dark side to be detrimental to the ecosystem, as it negatively influences actors' willingness to provide service to other members. Opportunism negatively affects relational trust, communication and commitment. From these discussions, it is evident that although network embeddedness presents some potential benefits to SMEs' innovation, these benefits could be negated by the relationship of dark side. We, therefore, state our second hypothesis as follows:

H2: Dark side of network has a negative moderating effect on the relationship between network embeddedness and the innovation performance of SMEs.

\subsection{Moderating Role of Relationship Ending Capability}

The term 'ending' means the resource ties and activities links are broken (Tidström \& Åhman, 2006). Relationship ending in this case does not refer to business relationships or alliances with an inbuilt natural end (Zaefarian et al., 2017). Mitrega et al. (2012) defined business relationship ending capability as "the set of activities and organizational routines which are implemented at the organizational level of the focal company aimed at terminating undesired business relationships." Business relationship endings are sometimes complex in nature, involving temporally and contextual embeddedness (Halinen \& Tähtinen, 2002), and could even result in litigations. Halinen \& Tähtinen (2002) divided business relationship ending into six stages. These are consideration, enabling, disengagement, communication, restoration, and sense making/ aftermath stages. Business relationship ending capability has been regarded as a crucial managerial task (Tidström \& Åhman, 2006). As for an effective ending strategy, firms should have the capability to evaluate partners input to the business, so as to effectively assess the cost and benefits of terminating the relationship with them (Kang, 2015). Havila \& Medlin (2012) also indicated earlier experience of relationship ending, appreciation of commitment types, and interdependence among partners play a key role in the success for ending process.

In strategic alliances, negative perceptions of joint benefits, negative prospects about future cooperation, and the lack of a win-win situation, significantly influenced alliance termination 
(Sadowski \& Duysters, 2008). Tidström \& Åhman (2006) indicated that business relationship ending is influenced by external, relational, and organizational factors. In a business-to-business customer relationship, a significant decrease in unprofitable business customers is realized by firms with a high level of relationship ending competency (Ritter \& Geersbro, 2011). Relationship ending capability frees up company's limited resources which are used to initiate and strengthen new and more fruitful business relationships, and was found to have a significant effect on the success of product innovation of firms (Zaefarian et al., 2017).

The relationship ending could be costly due to administrative, technical, legal and financial complications, but the use of effective ending strategy leads to a more favorable outcome (Alajoutsijärvi et al., 2000). Firms with relationship ending capability could easily withdraw from business relationships, and this would not have a detrimental effect on their operations. Alternatively, having relationship ending capability could also help these firms to effectively negotiate with business partners, since there are other viable options, apart from the current relationship. From the above discussions, it is evident that although dark side may have a negative influence on SMEs' network embeddedness and innovation performance relationship, SMEs with an effective relationship ending capability could reduce this negative effect of relationship dark side. Therefore, the last hypothesis is as follows:

H3: Relationship ending capability positively moderates the negative effect of the dark side of the relationship on network embeddedness and the innovation performance of SMEs.

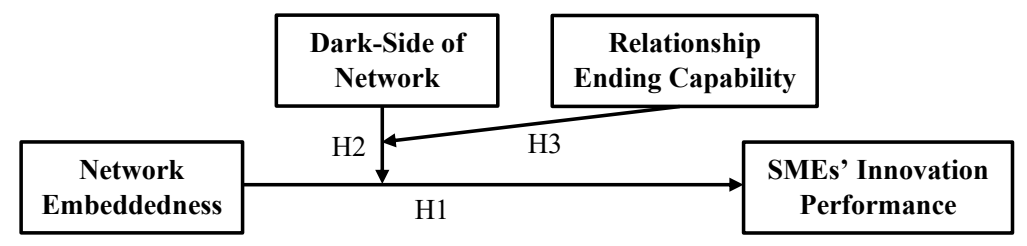

Fig. 1 - Theoretical framework. Source: own research

\section{RESEARCH OBJECTIVE, METHODOLOGY AND DATA}

The objective of this study is to assess the role of relationship ending capability in neutralizing the negative moderating effect of dark side in the relationship between network embeddedness and the innovation performance of SMEs.

\subsection{Firms Characteristics}

This study was placed in the context of SMEs in Ghana, where the definition of SMEs by the National Board for Small Scale Industries (NBSSI) was adopted. NBSSI (1990) classified firms with 6-29 employees as Small, and 30-99 employees as Medium enterprises. The firms sampled for the study were divided into manufacturing and service, of which the manufacturing constituted about $60 \%$ of the 388 selected SMEs (Table 1). The firms selected had employees ranging from 6-99, as per the definition of NBSSI. The SMEs studied had at least 5 years of 
operational experience, which was deemed adequate to have enough experience to respond to the research instrument. The respondents to the study were either owners managers (owners of the firms who doubled as managers) or employees managers. These respondents were chosen because of their in-depth knowledge of their firms, and their ability to contribute meaningfully to the study.

NBSSI being the governing body of SMEs in Ghana had the list of registered SMEs with the name of business, year of registration, nature of business, contact and location. Based on the list of SMEs obtained from NBSSI, the researchers targeted 1,000 firms which had operated for at least 5 years, and had full contact details such as email, phone and postal address. To ensure maximum participation of the firms, the questionnaire was designed in both electronic and printed versions. First, a printed version of the questionnaire, cover letter and a postage-paid return envelope were sent to the general managers of these SMEs. Secondly, the web link to the online questionnaire and a cover letter were also emailed to the SMEs. During the fourth week, the firms which had not responded to the researchers were randomly called by phone. The data collection started on 8th July 2019 and lasted until 12th August 2019. After 6 weeks of the data collection process, 388 questionnaires were appropriately filled in and returned. The response rate was $38.8 \%$ [(388/1000)*100]. Although the response rate of $38.8 \%$ looked small, with an estimated population of 10,000,000 SMEs, 95\% confidence level and 5\% margin of error, a sample size of 384 is ideal (Kirby et al., 2002). A sample size of 388 is, therefore, considered to be adequate enough for model estimation.

Tab. 1 - Firms characteristics. Source: own research

\begin{tabular}{|l|l|l|}
\hline Firms Characteristics & Frequency & Percentages (\%) \\
\hline Industry & 388 & $100 \%$ \\
\hline Manufacturing & 236 & 60.82 \\
\hline Service & 152 & 39.18 \\
\hline Size & 388 & $100 \%$ \\
\hline $6-29$ employees & 156 & 40.21 \\
\hline $30-99$ employees & 232 & 59.79 \\
\hline Age of firm & 388 & $100 \%$ \\
\hline 5-10 years & 97 & 25.00 \\
\hline $11-15$ years & 136 & 35.05 \\
\hline $16-20$ years & 93 & 23.97 \\
\hline Above 20 years & 62 & 15.98 \\
\hline
\end{tabular}

\subsection{Survey Questionnaire and Measures}

A structured questionnaire was developed, with the items adapted from past studies. There were four main variables in this study, which were Network Embeddedness (NET), Dark Side (DAS), Relationship Ending Capability (REC), and Innovation Performance (INP). Network embeddedness had three sub-dimensions, which were Relational Embeddedness (REE), Structural Embeddedness (STE), and Cognitive Embeddedness (COE). The observed items for 
these variables were adapted from Wang \& Chen (2012) and Gnyawau \& Madhavan (2001). The measures for the relationship of dark side were adapted from Pesäma et al. (2018), whiles those of relationship ending capability were also adapted from Forkmann et al. (2016). Finally, innovation items were also adapted from Abdallah et al. (2019).

Three firm specific variables were controlled for in this study, which were industry, age and size (measured by the number of employees). The type of industry coded as 0 -service and 1-manufacturing, was controlled for because every industry may have some unique characteristics that could influence innovation performance. Similarly, Boso et al. (2013) found out that firm size could significantly influence innovation activities in a firm. Wu et al. (2016) also indicated that R\&D activities across younger and older firms are different, which results in different innovation performance.

\subsection{Reliability and Validity of the Constructs}

Confirmatory Factor Analysis (CFA) was performed in Amos (v.23) and the results are presented in Table 2. Based on Hair et al.'s (2010) recommended fit indices criteria, it is concluded that our data appropriately fit the construct model. CMIN/DF is expected to be less than 3, CFI is expected to be greater than 0.9, PClose is expected to be greater than 0.05, RMR and RMSEA are also expected to be less than 0.08. These were all achieved after the analysis. As suggested by Fornell \& Larcker (1981), average variance extracted (AVE) is expected to be greater than 0.5. whiles composite reliability (CR) was also expected to be greater than 0.7 . These were also achieved from the analysis. Cronbach's Alpha (CA) for all constructs were also greater than 0.7 as expected (Brown, 2014).

Tab. 2 - Confirmatory factor analysis. Source: own research

\begin{tabular}{|l|l|}
\hline $\begin{array}{l}\text { Observed and Latent Variables } \\
\text { CMIN }=590.717 ; \mathrm{DF}=298 ; \mathrm{CMIN} / \mathrm{DF}=1.982 ; \mathrm{CFI}=.954 ; \mathrm{RMR}=.052 ; \\
\mathrm{RMSEA}=.048 ; \mathrm{PCl} \text {; }=.251\end{array}$ & $\begin{array}{l}\text { Std. Factor } \\
\text { Loading }\end{array}$ \\
\hline Network Embeddedness (NET): CA=0.848; CR=0.885; AVE $=0.720$ & 0.854 \\
\hline Relational Embeddedness (REE): CA=0.905; CR=0.911; AVE=0.719 & .810 \\
\hline Our firm embeds in networks with a large degree of familiarity with members. & .792 \\
\hline Our firm has a close relationship with network members. & .831 \\
\hline There is a high level of trust among our network members. & .950 \\
\hline There is a high level of transparency among our network members. & 0.921 \\
\hline Structural Embeddedness (STE): CA=0.818; CR=0.885; AVE=0.613 & .913 \\
\hline Our firm occupies a strategic position in its networks. & .627 \\
\hline Our firm has significant ties with its network members. & .900 \\
\hline $\begin{array}{l}\text { Our firm embeds in different networks, the members of which do not } \\
\text { frequently interact with members in either group. }\end{array}$ & .805 \\
\hline $\begin{array}{l}\text { Our firm embeds in networks whose members have a similar pattern of } \\
\text { relations with other members. }\end{array}$ & \\
\hline
\end{tabular}




\begin{tabular}{|c|c|}
\hline $\begin{array}{l}\text { Our firm embeds in networks with a high level of interconnection among its } \\
\text { members. }\end{array}$ & .617 \\
\hline Cognitive Embeddedness (COE): $\mathrm{CA}=0.846 ; \mathrm{CR}=0.906 ; \mathrm{AVE}=0.711$ & 0.763 \\
\hline Our firm embeds in networks with a common understanding. & .652 \\
\hline Our firm embeds in networks with a shared goal. & .871 \\
\hline Our firm embeds in networks with shared norms of behavior. & .978 \\
\hline Our firm embeds in networks with similar technological knowledge. & .840 \\
\hline \multicolumn{2}{|l|}{ Dark-side (DAS): $\mathrm{CA}=0.817 ; \mathrm{CR}=0.884 ; \mathrm{AVE}=0.660$} \\
\hline $\begin{array}{l}\text { On occasion, network members deceive fellow members about certain things } \\
\text { in order to protect their interests. }\end{array}$ & .758 \\
\hline $\begin{array}{l}\text { Network members sometimes promise to do things without actually following } \\
\text { through on these promises. }\end{array}$ & .653 \\
\hline Network members do not always act in accordance with our contracts. & .879 \\
\hline $\begin{array}{l}\text { Network members sometimes try to breach informal agreements to maximize } \\
\text { their own benefits. }\end{array}$ & .931 \\
\hline \multicolumn{2}{|l|}{ Relationship Ending Capability (REC): CA=0.902; CR=0.929; $\mathrm{AVE}=0.689$} \\
\hline $\begin{array}{l}\text { Our firm has established procedures for how to slowly discontinue business } \\
\text { relationships that are no longer desirable with network members. }\end{array}$ & .864 \\
\hline $\begin{array}{l}\text { We systematically minimize collaboration with network members that are no } \\
\text { longer beneficial to us. }\end{array}$ & .676 \\
\hline $\begin{array}{l}\text { Our firm has established a formal system to identify network member } \\
\text { relationships for which key performance indicators or agreed milestones have } \\
\text { not been met. }\end{array}$ & .667 \\
\hline $\begin{array}{l}\text { Our company has a formal system in place to assess the profit and costs } \\
\text { associated with existing network member relationships. }\end{array}$ & .968 \\
\hline $\begin{array}{l}\text { We systematically rank our network members according to their performance } \\
\text { in their business relationship with us. }\end{array}$ & .980 \\
\hline $\begin{array}{l}\text { We analyze the direct and indirect costs involved in ending a business } \\
\text { relationship with our network members. }\end{array}$ & .768 \\
\hline Innovation Performance (INP): CA=0.787; CR=0.895; AVE $=0.741$ & \\
\hline We are able to develop new products/services with speed. & .906 \\
\hline We are able to launch new products/services on time. & .782 \\
\hline Our new products/services are innovative. & .889 \\
\hline
\end{tabular}

The discriminant validity of the study is presented in Table 3, in which the squared-root of the AVEs ( AVEs) are compared with the inter-correlation scores. Finally, discriminant validity is shown, with the $\sqrt{A V E s}$ expected to be greater than the respective inter-correlation scores. In the analysis, the highest correlation score is -0.593 , which is less than the least $\sqrt{\text { AVE value of }}$ 0.812. The VIFs presented in Tab. 4 are less than 5, indicating there were no confounding effects among the variables (Dogbe et al., 2020a). 
Tab. 3 - Discriminant validity and descriptive analysis. Source: own research

\begin{tabular}{|l|l|l|l|l|l|l|l|}
\hline Variables & 1 & 2 & 3 & 4 & 5 & 6 & 7 \\
\hline $\begin{array}{l}\text { Industry } \\
(1)\end{array}$ & - & & & & & & \\
\hline Age (2) & 0.054 & - & & & & & \\
\hline Size (3) & 0.046 & $0.470 * *$ & - & & & & \\
\hline NET (4) & 0.215 & 0.178 & $0.313^{*}$ & 0.849 & & & \\
\hline DAS (5) & 0.199 & $0.344^{*}$ & $0.304^{*}$ & $-0.479^{* *}$ & 0.812 & & \\
\hline REC (6) & 0.131 & 0.173 & $0.317^{* *}$ & $0.344^{*}$ & $-0.440^{* *}$ & 0.830 & \\
\hline INP (7) & -0.169 & $-0.234^{*}$ & $0.266^{*}$ & $0.434^{* *}$ & $-0.593^{* *}$ & $0.562^{* *}$ & 0.861 \\
\hline
\end{tabular}

** $\sim$ P-value significant at 1\% (0.01)

$* \sim$ P-value significant at $5 \%(0.05)$

$\sqrt{ } \mathrm{AVE}$ are in bold and underlined

\section{RESULTS AND DISCUSSION}

\subsection{Results}

This study's conceptual framework (Figure 1) falls under the Model 3 of the Hayes (2017) statistical analysis approach. As such, the various paths estimated were based on the suggestions of Hayes (2017), which were the same as in the study presented by Dawson \& Richter (2006) on the three-way interaction effect. From the results presented in Table 1 (Model 1), industry and age had a negative effect on the innovation performance of SMEs, but only age had a significant effect. The size of firm also had a positive significant effect on innovation performance. In Models 2 to 4, however, none of the control variables had a significant effect.

In addressing the three hypotheses for this study, Models 2 to 4 were presented. Model 2 presented the effects of only the main variables, while Model 3 presented the effects of the main variables as well as the two-way interactions. Model 4 also presented the model by adding the three-way interaction to the Model 3. From Model 4, it is evident that network embeddedness and relationship ending capability had a positive significant effect on the innovation performance of SMEs, but the dark side had a negative significant effect.

The residual centering approach was adopted to calculate the interaction effects, for which only the residuals of the variables were multiplied (Dogbe et al., 2020a). The interaction between network embeddedness and the dark side (NETxDAS) had a negative significant effect on the innovation performance of SMEs. The interaction between relationship ending capability and network embeddedness (RECxNET) had a positive significant effect. Although the dark side had a direct negative effect on the innovation performance of SMEs, its interaction with relationship ending capability (RECxDAS) had a positive significant effect. Similarly, the threeway interaction among relationship ending capability, network embeddedness and the dark side (RECxNETxDAS) had a positive significant effect. From the analysis presented in Table 4 (Model 4), all three proposed hypotheses were supported. 
Tab. 4 - Moderation analysis. Source: own research

\begin{tabular}{|c|c|c|c|c|c|}
\hline Variables & Model 1 & Model 2 & Model 3 & Model 4 & VIF \\
\hline Constant & $\begin{array}{l}3.809 \\
\left(3.543^{* *}\right)\end{array}$ & $\begin{array}{l}2.111 \\
\left(2.960^{* *}\right)\end{array}$ & $\begin{array}{l}2.431 \\
\left(4.238^{* *}\right)\end{array}$ & $\begin{array}{l}1.108 \\
\left(3.487^{* *}\right)\end{array}$ & \\
\hline Industry & $-0.119(-0.966)$ & $\begin{array}{l}-0.091 \\
(-0.867)\end{array}$ & $\begin{array}{l}-0.071 \\
(-0.585)\end{array}$ & $\begin{array}{l}-0.055 \\
(-0.487) \\
\end{array}$ & 2.348 \\
\hline Age & $\begin{array}{l}-0.197 \\
\left(-2.114^{*}\right)\end{array}$ & $\begin{array}{l}-0.136 \\
(-0.446)\end{array}$ & $-0.125(-1.006)$ & $-0.115(-1.053)$ & 2.405 \\
\hline Size & $0.204\left(2.076^{*}\right)$ & $0.143(1.554)$ & $0.124(1.677)$ & \begin{tabular}{|l|l|}
$0.177(1.798)$ \\
\end{tabular} & 2.929 \\
\hline NET & & $\begin{array}{l}0.531 \\
(4.601 * *)\end{array}$ & $\begin{array}{l}0.420 \\
\left(2.787^{* *}\right)\end{array}$ & $\begin{array}{l}0.316 \\
\left(1.196^{* *}\right)\end{array}$ & 1.619 \\
\hline DAS & & $\begin{array}{l}-0.482 \\
\left(-3.286^{* *}\right)\end{array}$ & $\begin{array}{l}-0.383 \\
\left(-2.395^{*}\right)\end{array}$ & $\begin{array}{l}-0.372 \\
\left(-2.077^{*}\right)\end{array}$ & 1.917 \\
\hline REC & & $\begin{array}{l}0.355 \\
\left(2.867^{* *}\right)\end{array}$ & $\begin{array}{l}0.306 \\
\left(2.977^{* *}\right)\end{array}$ & $\begin{array}{l}0.408 \\
\left(3.196^{* *}\right)\end{array}$ & 1.345 \\
\hline NETxDAS & & & $\begin{array}{l}-0.456 \\
(-3.009 * *)\end{array}$ & $\begin{array}{l}-0.588 \\
\left(-3.301^{* *}\right)\end{array}$ & 2.280 \\
\hline RECXNET & & & $\begin{array}{l}0.341 \\
\left(2.815^{* *}\right)\end{array}$ & $0.311\left(2.032^{*}\right)$ & 1.898 \\
\hline RECxDAS & & & $0.305\left(2.341^{*}\right)$ & $0.316(2.420 *)$ & 1.848 \\
\hline RECxNETxDAS & & & & $\begin{array}{l}0.305 \\
\left(2.677^{* *}\right)\end{array}$ & 2.192 \\
\hline $\mathrm{R}^{2}$ & 0.292 & 0.498 & 0.572 & 0.625 & \\
\hline $\mathrm{F}$ & $9.989 * *$ & $13.746^{* *}$ & $11.529^{* *}$ & 9.191** & \\
\hline $\mathrm{R}^{2} \Delta$ & - & 0.206 & 0.074 & 0.053 & \\
\hline $\mathrm{F} \Delta$ & - & $5.506^{* *}$ & $3.150 * *$ & $2.329 *$ & \\
\hline
\end{tabular}

** P-value significant at $1 \%(0.01)$

* P-value significant at 5\% (0.05)

$\mathrm{T}$-values are in parentheses

\subsection{Discussion}

We have found that network embeddedness had a positive significant effect on the innovation performance of SMEs. The first hypothesis (HI) is thus supported: "H1: Network embeddedness has a significant effect on the innovation performance of SMEs." Just as in industry specific or large corporation studies, this study also finds that SMEs are able to draw innovation resources in their networks to improve their new product innovativeness and speed of development. High network embeddedness implies that a firm has a close relationship with network members, engages in a network with a high level of trust among members, occupies a strategic position in its networks, has significant ties with its network members, and engages in networks with a common understanding, having shared norms of behavior. Embedding in networks grants SMEs social capital, i.e. valuable assets (knowledge, human capital, knowledge, etc.) are placed at the disposal of firms in a network (Pèrez-Luño et al., 2011). As indicated by Lin et al. (2009), 
network embeddedness enhances knowledge exchanges among firms which complement their internal innovation resources. The current results are in agreement with some prior studies, which seems to suggest that exploitative and exploration innovations are enhanced through network embeddedness (Yan \& Guan, 2018). Gronum et al. (2012) indicated that both innovation and overall firm performance are influenced by a firm's network embeddedness. In the open innovation arena, Wang \& Chen (2012) found out that network embeddedness has an influence on disruptive innovation. On the whole, network embeddedness facilitates the transfer of resources such as technological knowledge, human resources, etc. for the innovation performance of SMEs.

The second hypothesis (H2) was stated as follows: "The dark side of a network has a negative moderating effect on the relationship between network embeddedness and the innovation performance of SMEs." It has been established that the innovation performance of SMEs is positively influenced by the firm's network embeddedness. This positive effect is, however, not automatic, as studies such as Pressey \& Tzokas (2004) have found that relationships are weakened over time because of reduced affective commitment. It is, however, this commitment towards the network that facilitates resource sharing among the network members. The very essence of engaging in a network is to draw resources from the network to supplement internal resources. Thus if the commitment towards knowledge sharing drops, the positive effect of network embeddedness also falls. The cause of this drop in commitment could be opportunistic behavior from members, which is referred to as the dark side of relationship. Anderson \& Jap (2005) have indicated that even relationships that seem to be very effective have an underlining vulnerability to a dark side. The study assessed the moderating role of the dark side on the positive relationship between network embeddedness and the innovation performance of SMEs. The analysis results supported the hypothesis that dark side had a negative moderating effect. This explains that SMEs that embed in networks with a high level of dark side would in turn have a negative effect on their innovation performance. Dark side effects relational trust, communication and commitment, and firms' willingness to transfer and share resources. Strong ties are blessings, but there is a threshold, beyond which it has an inverse effect on innovation knowledge, as opportunism by network members increases at that level (Noordhoff et al., 2011).

Finally, the last hypothesis (H3) is presented as follows: "H3: Relationship ending capability positively moderates the negative effect of the relationship of the dark side on network embeddedness and the innovation performance of SMEs." This was also supported by the analysis presented. As stated in the previous paragraph, the relationship of dark side has a negative moderating effect on the relationship between network embeddedness and the innovation performance of SMEs. Cutting ties with opportunistic network members may be ideal in such situations. This may, however, not be so for SMEs which have locked in their assets in current business relationships in the network, as they may be left with very limited resources for new network investment. This increases opportunity and the switching of costs. Relationship ending could also be costly for SMEs due to administrative, technical, legal and financial complications (Alajoutsijärvi et al., 2000). It was found that SMEs with relationship ending capability are able to reduce the negative effect of dark side. Relationship ending capability of SMEs, therefore, positively moderates the negative effect of dark side. Relationship ending capability encompasses 
the ability of SMEs to cut ties with the current business relationships in a network, and channel the resources into integrating into new business relationships to gain external resources for innovation (Padula, 2008). SMEs with relationship ending capability will also have the edge in terms of negotiations when interacting with network members, since they have the ability to easily exit the business relationship.

\section{CONCLUSION}

The study concludes that network embeddedness positively influences the innovation performance of SMEs. Inevitably, the dark side negatively moderated the relationship between network embeddedness and the innovation performance of SMEs. SMEs with effective relationship ending capability are, however, able to neutralize the negative moderating effect of the dark side by freeing up firm's limited resources for more fruitful business relationships. It is thus recommended that management of SMEs develop their relationship ending capability, which can save them from becoming entangled in unfruitful business relationships. Future studies could concentrate on the lock-in effect on business networks, i.e. how excessive resource allocation in one network hinders a firm from further investing in a new network.

\section{Acknowledgement}

This project was funded by The National Social Science Foundation of China (14BGL024): Research on the Open Innovation Mechanism and Promotional Policy of Small and Medium-sized Enterprises from the Perspective of Network Embeddedness. Senior Talent Project of Jiangsu University (08JDG055): Disruptive Innovation and Construction of SMEs Dynamic Competitive Advantage.

\section{References}

1. Abdallah, A. B., Dahiyat, S. E., \& Matsui, Y. (2019). Lean management and innovation performance: Evidence from international manufacturing companies. Management Research Review, 42 (2), 239-262. https://doi.org/10.1108/MRR-10-2017-0363

2. Abosag, I., Yen, D. A., \& Barnes, B. R. (2016). What is dark about the dark-side of business relationships? Industrial Marketing Management, 55, 5ᄀ-9.

3. Alajoutsijärvi, K., Möller, K., \& Tähtinen, J. (2000). Beautiful exit: how to leave your business partner. European Journal of Marketing, 34 (11/12), 1270-1290.

4. Anderson, E., \& Jap, S. D. (2005). The darkside of close relationships. MIT Sloan Management Review, 46 (3), 75-82.

5. Barney, J. (1991). Special theory forum the resource-based model of the firm: origins, implications, and prospects. Journal of Management, 17 (1), 97-98. https://doi. org/10.1177/014920639101700107

6. Boso, N., Story, V. M., \& Cadogan, J. W. (2013). Entrepreneurial orientation, market orientation, network ties, and performance: Study of entrepreneurial firms in a developing economy. Journal of Business Venturing, 28 (6), 708-727. https://doi.org/10.1016/j. jbusvent.2013.04.001

7. Brown, T. A. (2014). Confirmatory factor analysis for applied research. New York: Guilford Publications. 
8. Cortez, M. R., \& Johnston, W. J. (2019). Marketing role in B2B settings: evidence from advanced, emerging and developing markets. Journal of Business \& Industrial Marketing, 34 (3), 605-617. https://doi.org/10.1108/JBIM-04-2017-0089

9. Crosno, J. L., \& Dahlstrom, R. (2008). A meta-analytic review of opportunism in exchange relationships. Journal of the Academy of Marketing Science, 36 (2), 191-201. https://doi.org/10.1007/ s11747-007-0081-x

10. Dawson, J. F., \& Richter, A. W. (2006). Probing three-way interactions in moderated multiple regression: Development and application of a slope difference test. Journal of Applied Psychology, 91 (4), 917-926. https://doi.org/10.1037/0021-9010.91.4.917

11. Dogbe, C. S. K., Tian, H. Y., Pomegbe, W. W. K., Sarsah, S. A., \& Otoo, C. O. A. (2020a). Market Orientation and New Product Superiority among Small and Medium-Sized Enterprises (SMEs): The Moderating Role of Innovation Capability. International Journal of Innovation Management, 24 (5), 2050043. https://doi.org/10.1142/S1363919620500437

12. Dogbe, C. S. K., Tian, H., Pomegbe, W. W. K., Sarsah, S. A., \& Otoo, C. O. A. (2020b). Effect of network embeddedness on innovation performance of small and medium-sized enterprises. Journal of Strategy and Management, 13 (2), 181-197. https://doi.org/10.1108/JSMA-07-2019-0126

13. Echols, A., \& Tsai, W. (2005). Niche and performance: the moderating role of network embeddedness. Strategic Management Journal, 26 (3), 219-238. https://doi.org/10.1002/smj.443

14. Fang, S. R., Chang, Y. S., \& Peng, Y. C. (2011). Dark-side of relationships: A tensionsbased view. Industrial Marketing Management, 40 (5), 774-784. https://doi.org/10.1016/j. indmarman.2011.02.003

15. Forkmann, S., Henneberg, S. C., Naude, P., \& Mitrega, M. (2016). Supplier relationship management capability: a qualification and extension. Industrial Marketing Management, 57, 185ᄀ-200. https://doi.org/10.1016/j.indmarman.2016.02.003

16. Fornell, C., \& Larcker, D. F. (1981). Evaluating structural equation models with unobservable variables and measurement error. Journal of Marketing Research, 18 (1), 39-50. https://doi. org/10.1177/002224378101800104

17. Gilsing, V., Nooteboom, B., Vanhaverbeke, W., Duysters, G., \& van den Oord, A. (2008). Network embeddedness and the exploration of novel technologies: Technological distance,

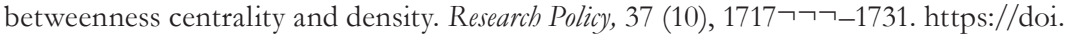
org/10.1016/j.respol.2008.08.010

18. Gnyawali, D. R., \& Madhavan, R. (2001). Cooperative networks and competitive dynamics: A structural embeddedness perspective. Academy of Management Review, 26 (3), 431 ᄀ-445. https:// doi.org/10.5465/amr.2001.4845820

19. Granovetter, M. (1985). Economic action and social structure: The problem of embeddedness. American Journal of Sociology, 91 (3), 481า-510. https://doi.org/10.1086/228311

20. Gronum, S., Verreynne, M. L., \& Kastelle, T. (2012). The role of networks in small and medium-sized enterprise innovation and firm performance. Journal of Small Business Management, 50 (2), 257-282. https://doi.org/10.1111/j.1540-627X.2012.00353.x 
21. Gulati, R., \& Singh, H. (1998). The architecture of cooperation: Managing coordination costs and appropriation concerns in strategic alliances. Administrative Science Quarterly, 43 (4), 781-814. https://www.jstor.org/stable/2393616

22. Hair, J. F., Black, W. C., Babin, B. J., \& Anderson, R. E. (2010). Multivariate data analysis: A global perspective (7th Ed.). Upper Saddle River, NJ: Pearson Education, Inc.

23. Halinen, A., \& Tähtinen, J. (2002). A process theory of relationship ending. International Journal of Service Industry Management, 13 (2), 163-180. https://doi.org/10.1108/09564230210425359

24. Havila, V., \& Medlin, C. J. (2012). Ending-competence in business closure. Industrial marketing management, 41 (3), 413-420. https://doi.org/10.1016/j.indmarman.2011.06.015

25. Hawkins, T. G., Pohlen, T. L., \& Prybutok, V. R. (2013). Buyer opportunism in businessto-business exchange. Industrial Marketing Management, 42 (8), 1266-1278. https://doi. org/10.1016/j.indmarman.2013.05.022

26. Hayes, A. F. (2017). Introduction to mediation, moderation, and conditional process analysis: A regressionbased approach. New York, NY, Guilford Publications. http://dm.darden.virginia.edu/ ResearchMethods/Templates.pdf

27. Hoholm, T., \& Olsen, P. I. (2012). The contrary forces of innovation: A conceptual model for studying networked innovation processes. Industrial Marketing Management, 41 (2), 344-356. https://doi.org/10.1016/j.indmarman.2012.01.013

28. Hortoványi, L., \& Szabó, R. Z. (2006). Knowledge and organization: A network perspective. Society and economy, 28 (2), 165-179. https://doi.org/10.1556/SocEc.28.2006.2.6

29. Huang, F., \& Rice, J. (2012). Openness in product and process innovation. International Journal of Innovation Management, 16 (04), 1250020. https://doi.org/10.1142/S1363919612003812

30. Hvolkova, L., Klement, L., Klementova, V., \& Kovalova, M. (2019). Barriers hindering innovations in small and medium-sized enterprises. Journal of Competitiveness, 11 (2), 51-67. https://doi.org/10.7441/joc.2019.02.04

31. Kang, J. (2016). Labor market evaluation versus legacy conservation: What factors determine retiring CEOs decisions about long-term investment? Strategic Management Journal, 37 (2), 389-405. https://doi.org/10.1002/smj.2234

32. Lin, J. L., Fang, S. C., Fang, S. R., \& Tsai, F. S. (2009). Network embeddedness and technology transfer performance in R\&D consortia in Taiwan. Technovation, 29 (11), 763-774. https://doi. org/10.1016/j.technovation.2009.05.001

33. Liu, F. H., Chen, L. J., \& Tsou, H. T. (2019). Suppliers' local network embeddedness and buyers' joint innovation: Mediating role of service innovation competence. International Marketing Review, 36 (3), 342-364. https://doi.org/10.1108/IMR-05-2018-0164

34. Luo, Y. (2006). Opportunism in Inter-firm Exchanges in Emerging Markets. Management and Organization Review, 2 (1), 121-147. https://doi.org/10.1111/j.1740-8784.2006.00032.x

35. Mele, C., Nenonen, S., Pels, J., Storbacka, K., Nariswari, A., \& Kaartemo, V. (2018). Shaping service ecosystems: exploring the dark-side of agency. Journal of Service Management, 29 (4), 521-545. https://doi.org/10.1108/JOSM-02-2017-0026 
36. Mitrega, M., Forkmann, S., Ramos, C., \& Henneberg, S. C. (2012). Networking capability in business relationships concept and scale development. Industrial Marketing Management, 41 (5), 739-751. https://doi.org/10.1016/j.indmarman.2012.06.002

37. Nahapiet, J., \& Ghoshal, S. (1998). Social capital, intellectual capital, and the organizational advantage. Academy of Management Review, 23 (2), 242-266. https://doi.org/10.5465/ amr.1998.533225

38. National Board for Small Scale Industries - NBSSI (1990). Supporting Micro \& Small-Scale Enterprises. A handbook on Enterprise Development Part 1. NBSSI," Print Solutions, Accra.

39. Noordhoff, C. S., Kyriakopoulos, K., Moorman, C., Pauwels, P., \& Dellaert, B. G. (2011). The bright side and dark-side of embedded ties in business-to-business innovation. Journal of Marketing, 75 (5), 34-52. https://doi.org/10.1509/jmkg.75.5.34

40. Padula, G. (2008). Enhancing the innovation performance of firms by balancing cohesiveness and bridging ties. Long Range Planning, 41 (4), 395-419. https://doi.org/10.1016/j. lrp.2008.01.004

41. Pérez-Luño, A., Medina, C. C., Lavado, A. C., \& Rodríguez, G. C. (2011). How social capital and knowledge affect innovation. Journal of Business Research, 64 (12), 1369-1376. https://doi. org/10.1016/j.jbusres.2011.01.014

42. Pesämaa, O., Dahlin, P., \& Öberg, C. (2018). Reduction of tension effects on partner evaluation. Marketing Intelligence \& Planning, 36 (4), 425-439. https://doi.org/10.1108/MIP-112017-0271

43. Pressey, A., \& Tzokas, N. (2004). Lighting up the "dark-side" of international export/import relationships: Evidence from UK exporters. Management Decision, 42 (5), 694ᄀ-708. https://doi. org/10.1108/00251740410538523

44. Ritter, T., \& Geersbro, J. (2011). Organizational relationship termination competence: A conceptualization and an empirical test. Industrial Marketing Management, 40 (6), 988-993. https://doi.org/10.1016/j.indmarman.2011.06.026

45. Sadowski, B., \& Duysters, G. (2008). Strategic technology alliance termination: An empirical investigation. Journal of Engineering and Technology Management, 25 (4), 305-320. https://doi. org/10.1016/j.jengtecman.2008.10.002

46. Selnes, F., \& Sallis, J. (2003). Promoting relationship learning. Journal of Marketing, 67 (3), 80-95. https://doi.org/10.1509/jmkg.67.3.80.18656

47. Tähtinen, J. (2002). The process of business relationship ending-its stages and actors. Journal of Market-Focused Management, 5 (4), 331-353. https://doi.org/10.1023/ B:JMFM.0000008073.86880.6d

48. Tidström, A., \& Åhman, S. (2006). The process of ending inter-organizational cooperation. Journal of Business \& Industrial Marketing, 21 (5), 281-290. https://doi. org/10.1108/08858620610681588

49. Tsai, M. C., Lai, K. H., Lloyd, A. E., \& Lin, H. J. (2012). The dark-side of logistics outsourcing-unraveling the potential risks leading to failed relationships. Transportation Research Part E: Logistics and Transportation Review, 48 (1), 178-189. https://doi.org/10.1016/j. tre.2011.07.003 
50. Valente, T. W. (2005). Network models and methods for studying the diffusion of innovations. Models and methods in social network analysis, 28, 98. https://www.researchgate.net/profile/ Thomas_Valente/publication/284143679_Network_models_and_methods_for_studying_ the_diffusion_of_innovations/links/58470f3d08ae61f75ddfe651.pdf

51. Villena, V. H., Revilla, E., \& Choi, T. Y. (2011). The dark-side of buyer-supplier relationships: A social capital perspective. Journal of Operations Management, 29 (6), 561-576. https://doi. org/10.1016/j.jom.2010.09.001

52. Wang, X., \& Yang, Z. (2013). Inter-firm opportunism: a meta-analytic review and assessment of its antecedents and effect on performance. Journal of Business \& Industrial Marketing, 28 (2), 137-146. https://doi.org/10.1108/08858621311295272

53. Wang, Z., \& Chen, J. (2012). Knowledge network embeddedness, absorptive capacity and disruptive innovation performance: A comparative case study in open innovation arena. In 2012 IEEE International Conference on Management of Innovation \& Technology (ICMIT), 452-457. https://doi.org/10.1109/ICMIT.2012.6225848

54. Wasserman, S., \& Faust, K. (1994). Social network analysis: Methods and applications. https:// books.google.com.gh/books?hl=en\&lr=\&id=CAm2DpIqRUIC\&oi=fnd\&pg=PR21\&dq=Was serman $+\% 26+$ Faust, $+1994+\& o t s=H x$ GpvfWHOe\&sig=Esb4Wc4NLzr7FwUJdIXDw0hS0Q w\&redir_esc $=\mathrm{y} \# \mathrm{v}=$ onepage $\& \mathrm{q}=$ Wasserman $\% 20 \% 26 \% 20 \mathrm{Faust} \% 2 \mathrm{C} \% 201994 \& \mathrm{f}=$ false

55. Williamson, O. E. (1975). Markets and Hierarchies. New York: Free Press.

56. Wu, J., Wang, C., Hong, J., Piperopoulos, P., \& Zhuo, S. (2016). Internationalization and innovation performance of emerging market enterprises: The role of host-country institutional development. Journal of World Business, 51 (2), 251-263. https://doi.org/10.1016/j. jwb.2015.09.002

57. Xiaobao, P., Wei, S., \& Yuzhen, D. (2013). Framework of open innovation in SMEs in an emerging economy: firm characteristics, network openness, and network information. International Journal of Technology Management, 62(2/3/4), 223-250. https://doi.org/10.1504/ IJTM.2013.055142

58. Yan, Y., \& Guan, J. (2018). Social capital, exploitative and exploratory innovations: The mediating roles of ego-network dynamics. Technological Forecasting and Social Change, 126, 244-258. https://doi.org/10.1016/j.techfore.2017.09.004

59. Zaefarian, G., Forkmann, S., Mitręga, M., \& Henneberg, S. C. (2017). A capability perspective on relationship ending and its impact on product innovation success and firm performance. Long Range Planning, 50 (2), 184-199. https://doi.org/10.1016/j.lrp.2015.12.023 


\section{Contact Information}

Prof. Hongyun Tian, Ph.D.

Jiangsu University

School of Management

P. R. China

E-mail:twfb7522@163.com

Courage Simon Kofi Dogbe, Ph.D.

Akenten Appiah-Menka University of Skills Training and Entrepreneurial Development Faculty of Business Education

Kumasi, Ghana.

E-mail: courageskd@gmail.com

ORCID: 0000-0003-4658-4067

Prof. Bylon Abeeku Bamfo, Ph.D.

Kwame Nkrumah University of Science and Technology

School of Business

Ghana

E-mail:babamfo@hotmail.com

ORCID: 0000-0002-3203-9482

Wisdom Wise Kwabla Pomegbe, Ph.D.

Cape Coast Technical University

Department of Marketing

Cape Coast, Ghana.

E-mail: wisdom.pomegbe@cctu.edu.gh

ORCID: 0000-0002-7552-9801

Prasad Siba Borah, Ph.D.

Jiangsu University

School of Management

P. R. China

E-mail:siba@ujs.edu.cn 